Jurnal Sastra Indonesia

\title{
SPEECH BEHAVIOR EXPRESSION ON TRUCK IN SISEMUT UNGARAN TERMINAL
}

\section{Muhamad Haekal $^{\bowtie}$, Hari Mardikantoro, Ahmad Syaifudin}

Jurusan Bahasa dan Sastra Indonesia, Fakultas Bahasa dan Seni, Universitas Negeri Semarang, Indonesia

\section{Info Artikel Abstrak}

Sejarah Artikel:

Diterima Januari 2019

Disetujui Februari 2019

Dipublikasikan Maret 2019

\section{Keywords:}

acts of speech; effect of speech acts

\begin{abstract}
Tujuan yang dicapai dalam penelitian ini adalah untuk mendeskripsikan bentuk tindak tutur dan efek dari tindak tutur pada bak truk di Terminal Sisemut Ungaran. Analisis data dilakukan dengan metode padan. Berdasarkan hasil analisis, diketahui bahwa pada penggalan wacana pada bak truk di Terminal Sisemut Ungaran terdiri dari jenis tindak tutur konstatif, performatif, lokusi, ilokusi, perlokusi, representatif, direktif, ekspresif, komisif, langsung harfiah, langsung tak harfiah, tak langsung harfiah, tak langsung tak harfiah. Selain itu, efek yang ditimbulkan dari tindak tutur dalam penggalan tuturan wacana pada bak truk ditemukan dalam penelitian ini efek positif meliputi introspeksi, mendorong. melegakan, memaklumi, bersimpati, menurut. Efek negatif dalam penelitian ini meliputi tersinggung, dewasa.
\end{abstract}

\section{Abstract}

The objectives in this research is to describe the from of speech acts and the effect of speech acts and the effect of speech acts on the tank truck in Terminal Sisemut Ungaran. Data analysis is done by method of padan. Based on the results of the analysis, it is known that the discourse fragments on the truck at the terminal of ungaran sisemut consisted of the type of speech act konstatif, performative, locution, ilocution, perlocution, representative, directive, exspressive, commissive, directly literal, directly not literally, not literally, not directly literal. Besides the effects of speech acts in discourse on the truck found positive effects include introspection, push, a relief, tolerance, sympathy, according. Negative effects in this study include offense, adult. 


\section{PENDAHULUAN}

Terminal Sisemut merupakan tempat titik pertemuan antara penumpang dan barang yang masuk dan keluar, lokasinya berada di Kecamatan Ungaran Barat, Kabupaten Semarang. Sebagai layaknya terminal, berbagai macam kendaraan pengangkut yang berlalu lalang masuk dan keluar. Di belakang bak truk angkutan barang tersebut terdapat gambar dan tulisan yang seringkali membuat orang tertawa melihatnya bahkan sampai penasaran ingin mengetahui apa maksud dari gambar dan tulisan sesungguhnya. Gambar dan tulisan inilah yang menjadi keunikan dari bak truk yang pada mulanya hanya sebagai kendaraan pengangkut, sekarang memiliki fungsi lain yaitu terjadinya sebuah komunikasi.

Berdasarkan informasi dari salah satu sopir truk yang bernama Pak Turyono selaku ketua paguyuban truk angkutan di Terminal Sisemut, truk yang ada di sini cukup bervariasi ada truk pasir, angkutan barang-barang dan banyak variasi gambarnya. Ada variasi bentuk gambar visual yang berupa figur perempuan, tokoh agama hingga tokoh penting pejabat negara, yang dibubuhi tulisan atau kata-kata penjelas. Tulisan yang disertai gambar tersebut secara tidak langsung dapat menarik perhatian pengguna jalan raya untuk melihat dan membacanya.

Berdasarkan studi awal peneliti, di Terminal Sisemut terdapat paguyuban pangkalan truk muatan yang mayoritas anggotanya adalah penduduk asli di sekitar terminal. Di sana mereka membentuk sebuah paguyuban antar sesama sopir. Rata-rata mereka memiliki kendaraan truk dan mengendarai sendiri truk mereka. Setelah terjun di lapangan, peneliti menemukan 43 truk yang melintas dan terparkir di Terminal Sisemut Ungaran. Pada 29 belakang truk atau bak truk di antaranya terdapat keunikan berupa tulisan yang disertai gambar bersifat peringatan, ajakan, situasi sosial dan sebagainya.

Sebagai contoh tuturan dalam wacana bak truk yang bertulisakan "Surga di telapak kaki ibu" merupakan jenis tindak tutur perlokusi, sebab tuturan tersebut memberikan suatu efek kepada mitra tutur. Pada wacana tersebut memiliki maksud yaitu sehebat-hebatnya manusia tetap harus ingat bahwa masih ada orang tua dan Tuhan , sehingga hendaknya merasa kecil diri dan jangan menjadi sombong. Alasan tutuan tersebut termasuk tindak tutur perlokusi adalah pada wacana tersebut memberikan efek 'dorongan' pada orang yang membacanya agar termotivasi untuk memuliakan orang tua (ibu). Dalam agama Islam juga dijelaskan bahwa dari seorang ibu terletak surga yaitu restunya. Bila kita hendak mendapatkan surga maka patuhlah pada ibu. Tuturan tersebut juga mengandung pesan moral yang mengingatkan bahwa seorang anak wajib berbakti kepada kedua orang tua terutama ibu. Selain itu, tuturan tersebut juga terdapat maksud yang menunjukan rasa kepedulian dari penutur untuk memengaruhi mitra tutur agar dapat memuliakan ibu.

Berdasarkan uraian data tersebut, peneliti tertarik untuk melakukan penelitian lebih dalam tentang tuturan di bak truk dengan mengambil judul "Tindak Tutur Pada Wacana Bak Truk di Terminal Sisemut Ungaran". Secara lebih lanjut, penelitian ini bertujuan untuk mengkaji tuturan secara lebih dalam berkaitan dengan tindak tutur serta menganalisis efek yang dimunculkan dari mitra tutur dalam menginterpretasikan dan mengetahui maksud tuturan yang disampaikan penutur.

\section{METODE PENELITIAN}

Penelitian ini menggunakan dua pendekatan, yaitu pendekatan teoretis dan metodologis. Pendekatan metodologis yang digunakan pada penelitian ini adalah pendekatan kualitatif yang bersifat deskriptif. Pendekatan kualitatif digunakan karena data yang dikumpulkan berupa teks/gambar bukan berupa angka-angka.

Penelitian ini berlokasi di Terminal Sisemut, Kecamatan Ungaran Barat, Kabupaten Semarang. Lokasi ini dipilih karena selain fungsinya sebagai terminal, terdapat pangkalan truk angkutan yang menarik untuk menjadi bahan kajian penelitian. Pada lokasi ini data penelitian sudah bervariasi, dan mitra tutur dari masyarakat yang melihat beraneka ragam dari status sosial, dan tingkat pendidikan. Selain itu, lokasi penelitian yang berdekatan dengan kampus Universitas Negeri Semarang (Unnes).

Dalam penelitian ini terdiri atas data primer dan sekunder. Data primer berupa wacana pada bak truk yang diambil peneliti langsung di Terminal Sisemut Ungaran berjumlah 32 truk. Selanjutnya data sekunder adalah data yang diperoleh peneliti dan tidak bersumber langsung dari tuturan para penutur, dalam hal ini peneliti melakukan wawancara terhadap 3 subjek informan mitra tutur (SI) yaitu masyarakat di sekitar terminal yang melihat tuturan wacana pada bak truk sebagai perwakilan dari masyarakat. Sumber data yang didapat dalam penelitian ini yaitu wacana pada bak truk yang mangkal di Terminal Sisemut Ungaran.

Metode pengumpulan data yang digunakan adalah metode simak dan metode cakap karena berupa penyimakan dan wawancara (Sudaryanto, 2015:203-209). Teknik pengumpulan data dalam penelitian ini meliputi teknik rekam, 
teknik catat, teknik cakap semuka. Teknik rekam dilakukan menggunakan kamera telepon seluler untuk mendokumentasi. Teknik catat dilakukan untuk mencatat data-data yang ditemukan pada kartu data dan dilanjutkan dengan mengklasifikasikan jenis tindak tutur. Teknik cakap semuka digunakan untuk memancing percakapan langsung dengan narasumber.

Metode yang digunakan untuk analisis data dalam penelitian ini adalah metode padan. Metode padan merupakan metode yang menghubungkan masalah bahasa dengan hal yang berada di luar bahasa. Penelitian ini menggunakan metode padan dengan teknik pilah unsur penentu. Adapun sub jenis alat penentu yang digunakan yaitu sub jenis ke lima alat penentunya bahasa lain yaitu tulisan dan mitra wicara (Sudaryanto, 2015:15). Langkah-langkah analisis data pada penelitian ini sebagai berikut.

(1) Memilah data yang kira-kira memenuhi dan layak.

(2) Menganalisis tuturan dalam jenis tindak tutur.

(3) Mendeskripsikan makna dari hasil wawancara.

Penelitian ini menggunakan penyajian hasil analisis data secara infromal. Penyajian secara infromal adalah penyajian hasil analisis data dengan menggunakan kata-kata biasa (Sudaryanto, 2015:15). Hasil penyajian analisis data penelitian ini dibagi menjadi 2, yaitu: mendeskripsikan tuturan termasuk jenis tindak tutur apa saja, mendeskripsikan efek tindak tutur pada mitra tutur.

\section{HASIL PENELITIAN DAN PEMBAHASAN}

Pembahasan yang pertama dalam penelitian ini adalah jenis tindak tutur yang meliputi tindak tutur konstatif, performatif, lokusi, ilokusi, perlokusi, representatif, direktif, ekspresif, komisif, langsung harfiah, langsung tak harfiah, tak langsung harfiah, tak langsung tak harfiah.

Contoh analisis tindak tutur konstatif adalah tindak tutur yang menyatakan sesuatu yang kebenarannya dapat diuji benar atau salah. Kekonstatifan tuturan tersebut dapat dibuktikan dengan cara menguji benar atau salah isi dari tuturan itu. $\begin{array}{cll}\text { (1) KONTEKS : PADA } & \text { BELAKANG BAK } \\ \text { TRUK TERDAPAT TULISAN YANG }\end{array}$ MENGGAMBARKAN ORANG BISA MUDAH NGILER TERPENGARUH KARENA HARTA DAN TAHTA BUKAN HANYA TIDUR MIRING.

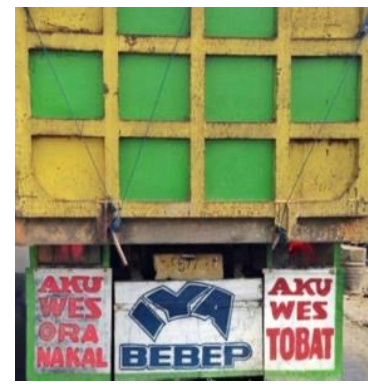

(Data 24 Maret 2015)

Tuturan (1) yang berbunyi "Gwa ga ngiler harta dan tahta gwa ngiler kalo tidur miring" merupakan jenis tindak tutur konstatif, sebab tuturan tersebut menyatakan sesuatu yang dapat diuji kebenarannya dengan pengetahuan yang ada. Maksud dari tuturan tersebut penutur ngiler apabila tidur miring bukan dengan harta dan tahta. Alasan disebut sebagai tindak tutur performatif karena kebenarannya dapat dibuktikan yaitu, ketika manusia tidur dengan posisi miring, biasanya mulut akan terbuka sehingga air liur keluar dari dalam mulut yang terbuka.

Contoh tuturan performatif. Tindak tutur performatif yaitu tuturan yang dilakukan penutur untuk melakukan sesuatu tindakan. Berikut ini tindak tutur performatif dalam wacana pada bak truk.

(2) KONTEKS : PADA BAGIAN BAWAH BELAKANG BAK TRUK TERDAPAT TULISAN YANG MENGGAMBARKAN PENUTUR BERJANJI KEPADA KEKASIHNYA UNTUK BERTOBAT TIDAK AKAN NAKAL LAGI.

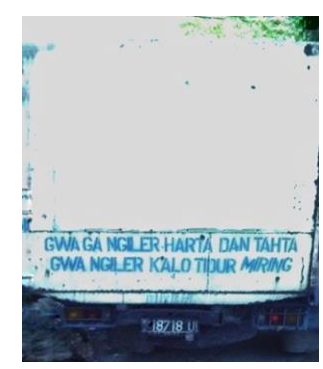

(Data 24 Maret 2015)

Tuturan (2) yang berbunyi "Aku wes ora nakal iya bebep aku wes tobat" merupakan jenis tindak tutur performatif, sebab tuturan tersebut merupakan tindakan melakukan sesuatu dengan membuat ujaran itu sendiri. Maksud dari tuturan tersebut sang penutur berjanji kepada kekasihnya untuk bertobat tidak akan kembali melakukan tindakan nakalnya lagi. Alasan disebut sebagai 
tindak tutur performatif karena penutur mengatakannya sendiri dan melakukan tindakan dari tuturannya sendiri. Tuturan tersebut merupakan tuturan yang sahih, karena penutur sudah bertobat sehingga tidak mungkin bertindak nakal kembali.

Contoh tuturan lokusi. Tindak tutur lokusi adalah tindak tutur yang dimaksudkan untuk menyatakan sesuatu. Maksudnya lokusi merupakan tindak tutur yang diujarkan dengan suatu makna atau acuan tertentu Di dalam tindak tutur lokusi, tidak dipermasalahkan maksud atau fungsi tuturan. Berikut ini tindak tutur lokusi dalam wacana pada bak truk.

(3) KONTEKS : PADA BAGIAN BELAKANG BAK TRUK TERDAPAT TULISAN YANG MENGGAMBARKAN PEKERJAAN SEBAGAI SUPIR BUKAN SEBAGAI PROFESI TAPI MENJADI HOBY.

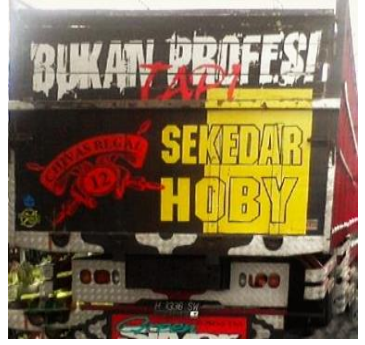

(Data 19 Maret 2015)

Tuturan (3) yang berbunyi "Bukan profesi tapi sekedar hoby" merupakan jenis tindak tutur lokusi, sebab tuturan tersebut merupakan sebuah pernyataan mengenai pekerjaannya sebagai supir. Maksud dari tuturan tersebut merupakan sebuah pernyataan mengenai apa yang dikerjakannya sebagai supir. Alasan disebut sebagai tindak tutur lokusi karena, pada wacana tersebut tidak meminta pertanggungjawaban dari mitra tutur. Melainkan hanya menjelaskan bahwa pekerjaan yang dikerjakannya sebagai supir bukanlah sebagai profesi keahliannya melainkan sebagai hoby.

Contoh efek tindak tutur positif. Efek Introspeksi adalah dampak yang bertujuan sebagai peninjauan atau koreksi terhadap (perbuatan, sikap, kelemahan, kesalahan, dan sebagainya) diri sendiri. Berikut ini merupakan efek introspeksi dalam wacana pada belakang bak truk.

(4) KONTEKS : PADA BAGIAN BELAKANG BAK TRUK TERDAPAT TULISAN YANG MENGGAMBARKAN WANITA BERKERUDUNG HANYA SEBAGAI PENGHIAS SAJA TIDAK MENDALAMI ESENSI DARI BERKERUDUNG YANG BENAR.

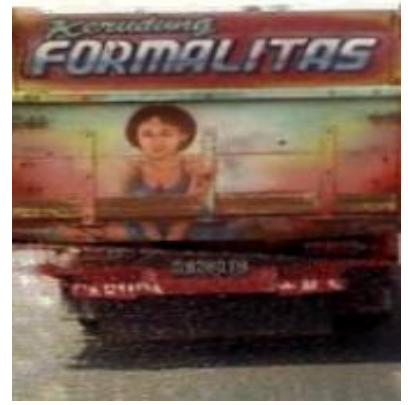

(Data 9 April 2015)

Pada tuturan (4) "Kerudung formalitas" memberikan efek bagi mitra tutur yang melihatnya yaitu efek introspeksi. Mitra Tutur 1 (Pa Gino) menjelaskan setelah melihat tuturan "Kerudung formalitas" mengartikan yaitu "pada perempuan yang mengaku berpura-pura sholehah tetapi tidak mengerti tata cara berkerudung lebih baik tidak berkerudung sekalian, dari pada berkerudung tapi tidak menjaga makna dari pemakaian kerudung itu sendiri." Mitra Tutur 2 (Pa Suratmin), menjelaskan setelah melihat tuturan "Kerudung formalitas" mengartikan "wanita zaman sekarang berkerudung tetapi sama saja seperti tidak berkerudung, khususnya yang ikut trend hijab." Mitra Tutur 3 (Pa Wahono), menjelaskan setelah melihat tuturan "Kerudung formalitas" mengartikan "wanita perlu bisa menjaga diri dengan menutup aurat sesuai syariat yang ada."

Dari ke tiga mitra tutur yang melihat tuturan "kerudung formalitas" dapat ditarik kesimpulan dari pemahaman mereka yaitu perlunya sikap introspeksi bagi wanita yang menggunakan kerudung untuk lebih memahami tentang pemakaian dari kerudung itu sendiri. Penggambaran itu dapat dilihat pada konteks yang ditampilkan secara visual wanita berpakaian sexy menggoda yang mendukung maksud dari tuturan.

Contoh efek tindak tutur negatif. Efek tersinggung adalah dampak yang terjadi pada mitra tutur, sehingga mitra tutur menjadi marah karena tidak sepantasnya. Berikut ini merupakan efek tersinggung dalam wacana pada belakang bak truk.

(5) KONTEKS PADA BAGIAN BELAKANG BAK TRUK TERDAPAT TULISAN YANG MENGGAMBARKAN HARUS MENJAGA OMONGAN JANGAN ASAL BERUCAP BISA MENJADI SALAH BERUCAP.

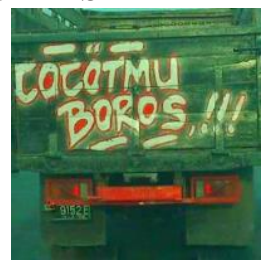

(Data 19 Maret 2015) 
Pada tuturan (5) "Cocotmu boros.!!!" memberikan efek bagi mitra tutur yang melihatnya yaitu efek tersinggung. Mitra Tutur 1 (Pa Gino) menjelaskan setelah melihat tuturan "Cocotmu boros.!!!" mengartikan yaitu "banyak omongan." Mitra Tutur 2 (Pa Suratmin) menjelaskan setelah melihat tuturan "Cocotmu boros.!!!" mengartikan yaitu "mulutnya tidak bisa dijaga, tetapi menggunakan kata-kata yang kasar." Mitra Tutur 3 (Pa Wahono) menjelaskan setelah melihat tuturan "Cocotmu boros.!!!" mengartikan yaitu "jagalah ucapan jangan asal berucap."

Dari ke tiga mitra tutur yang melihat tuturan "Cocotmu boros.!!!" dapat ditarik kesimpulan efek dari pemahaman mereka yaitu mereaka tersinggung, karena kata-kata yang digunakan menggunakan Bahasa Jawa yang kasar, tidak sopan untuk diucapakan umum. Untuk maksud tuturan bagus tetapi kata-kata yang digunakan kasar tidak sopan.

\section{PENUTUP}

Berdasarkan rumusan masalah, tujuan penelitian, dan pembahasan yang telah diuraikan pada bab sebelumnya, simpulan penelitian ini diuraikan sebagai berikut.

1. Jenis dari tindak tutur pada wacana bak truk di terminal sisemut ungaran, terdiri dari tindak tutur konstatif, performatif, lokusi, ilokusi, perlokusi, representatif, direktif, ekspresif, komisif, langsung harfiah, langsung tak harfiah, tak langsung harfiah, tak langsung tak harfiah.

2. Adapun efek yang ditimbulkan dari tindak tutur dalam penggalan tuturan wacana pada bak truk ditemukan efek positif yaitu, introspeksi, mendorong. melegakan, memaklumi, bersimpati, menurut. Efek negatif yaitu tersinggung, dewasa.

\section{DAFTAR PUSTAKA}

Cahyono, Bambang Yudi. 1995. Kristal-kristal Ilmu Bahasa. Surabaya: Airlangga University Press.

Fairus, Dian. 2007. Jenis dan Fungsi Tindak Tutur Pemandu Wisata di Bali. Skripsi. Universitas Negeri Semarang.

Handayani, Tri. 2004. Tindak Tutur Perlokusi dan Efeknya Dalam Wacana Dakwah AA Gym. Skripsi. Universitas Negeri Semarang.

Hidayah, Nur. 2009. Jenis Tindak Tutur dan Pelanggaran Prinsip Kesantunan dalam Wacana Empata Mata di Trans 7. Skripsi. Universitas Negeri Semarang.

Ibrahim, A.S. 1993. Kajian Tindak Tutur. Surabaya: Usaha Nasional.
Khadriyah. 2005. Tuturan Ilokusi Perawat di RS Umum Ungaran. Skripsi. Universitas Negeri Semarang.

Kurzon. 1998. "The speech act status of incitement : perlocutionary acts revisited. Journal of Pragmatics. July 2015. Nomor 29. Hal. 571-596. Israel: Haifa University.

Leech, Geoffrey. 1993. Prinsip-Prinsip Pragmatik (Diterjemahkan oleh Oka). Jakarta: Balai Pustaka.

Levinson, S. C. 1983. Pragmatics. Cambridge: Cambridge University Press.

Marcu, Daniel. 1999. 'Perlocutions: The Achilles' Heel of Speech Act Theory". Journal of Pragmatics. October 2000. Nomor 32. Hal 1719-1741. USA: University of Southern California.

Mulyana, Deddy. 2005. Ilmu Komunikasi Suatu Pengantar. Bandung: PT. Remaja Rosdakarya.

Nadar, F.X. 2009. Pragmatik dan Penelitian Pragmatik. Yogyakarta: Graha Ilmu.

Riyadi. 2006. Jenis dan Fungsi Tindak Tutur Karttun Kritik pada Seputar Semarang Harian Suara Merdeka Edisi JanuariDesember 2005. Skripsi. Universitas Negeri Semarang.

Rohmadi, Muhammad. 2004. Pragmatik Teori dan Analisis. Yogyakarta : Lingkar Media.

Rustono. 1999. Pokok-Pokok Pragmatik. Semarang: IKIP Semarang Press.

Sudaryanto. 2015. Metode dan Aneka Teknik Analisis Bahasa. Yogyakarta: Sanata Dharma University Press.

Tarigan, Henry Guntur. 1987. Pengajaran Pragmatik. Bandung: Angkasa.

Wijana, I Dewa Putu. 1996. Speech Acts: An Essay in The Philophy of Language. Yogyakarta: Andi.

Moeloeng, L. J. 2015. Metodologi Penelitian Kualitatif. Bandung: Remaja Rosdakarya. 